\title{
Fragment-wise design of inhibitors to 3C Proteinase from Enterovirus 71
}

Caiming $\mathrm{Wu}^{\mathrm{a}, \mathrm{b}, 1}$, Lanjun Zhang ${ }^{\mathrm{b}, 1}$, Peng $\mathrm{Li}^{\mathrm{c}, 1}$, Qixu Cai ${ }^{\mathrm{b}, 1}$, Xuanjia Peng ${ }^{\mathrm{c}}$, Ke $\mathrm{Yin}^{\mathrm{c}}$, Xinsheng Chen ${ }^{\mathrm{c}}$, Haixia Ren ${ }^{\mathrm{b}}$, Shilin Zhong ${ }^{\mathrm{b}}$, Yuwei Weng ${ }^{\mathrm{d}}$, Yi Guan ${ }^{\mathrm{e}}$, Shuhui Chen ${ }^{\mathrm{c}}$, Jinzhun $\mathrm{Wu}^{\mathrm{a}, *}$, Jian $\mathrm{Li}^{\mathrm{c},}$ *, Tianwei Lin ${ }^{\mathrm{b}, *}$

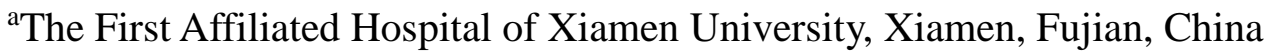

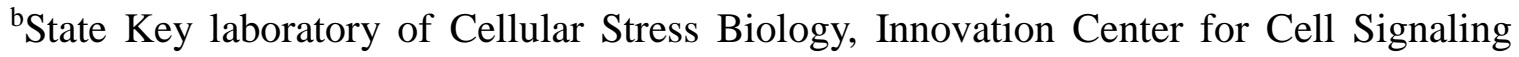

Network, State-province Joint Engineering Laboratory of Targeted Drugs from Natural

Products, School of Life Sciences, Xiamen University, Xiamen, Fujian, China

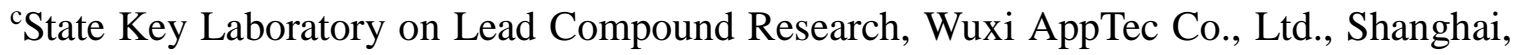
China;

${ }^{\mathrm{d}}$ Fujian Center for Disease Control, Fuzhou, Fujian, China

'State Key Laboratory for Emerging Infectious Diseases, The University of Hong Kong, Hong Kong SAR, P.R. China

${ }^{1}$ These authors contributed equally to this work.

*Corresponding Authors: twlin@xmu.edu.cn,jian_li@wuxiapptec.com, 1923731201@qq.com 


\section{ABTRACT}

Background: Enterovirus 71 (EV71) is a causative agent of hand, foot and mouth disease (HFMD), which can spread its infection to central nervous and other systems with severe consequence. A key factor in the replication of EV71 is its $3 \mathrm{C}$ proteinase $\left(3 \mathrm{C}^{\mathrm{pro}}\right)$, a significant drug target. Peptidomimetics were employed as inhibitors of this enzyme for developing antivirals. However, the peptide bonds in these peptidomimetics are a source of low bioavailability due to their susceptibility to protease digestion. To produce non-peptidomimetic inhibitors by replacing these peptide bonds, it would be important to gain better understanding on the contribution of each component to the interaction and potency.

Methods: A series of compounds of different lengths targeting $3 \mathrm{C}^{\text {pro }}$ and having an $\alpha, \beta$-unsaturated ester as the warhead were synthesized and their interactions with the enzyme were evaluated by complex structure analyses and potency assays for a better understanding on the relationship between potency and evolution of interaction.

Results: The P2 moiety of the compound would need to be oriented to interact in the S2 site in the substrate binding cleft and the P3-P4 moieties were required to generate sufficient potency. A hydrophobic terminal group will benefit the cellular uptake and improve the activity in vivo.

Conclusions and general significance: The data presented here provide a basis for designing a new generation of non-peptidomimetics to target EV71 3C $\mathrm{C}^{\text {pro }}$. 


\title{
Keywords
}

Hand, foot and mouth disease/3C proteinase/peptidomimetics/drug design/rupintrivir

\begin{abstract}
Abbreviations used: hand, foot and mouth disease, HFMD; $3 \mathrm{C}$ proteinase, $3 \mathrm{C}^{\mathrm{pro}}$; enterovirus 71, EV71; human rhinovirus, HRV; nuclear magnetic resonance, NMR; reverse phase-high pressure liquid chromatography, RP-HPLC; trifluoroacetic acid, TFA; liquid chromatography, LC; mass spectrometry, MS; fluorescence resonance energy transfer, FRET; dimethyl sulfoxide, DMSO; half maximal inhibitory concentration, $\mathrm{IC}_{50}$; half maximal effective concentration, $\mathrm{EC}_{50}$; micromolar, $\mu \mathrm{M}$; root mean square deviation, r.m.s.d; dichloromethane, DCM;

1-[Bis(dimethylamino)methylene]-1H-1,2,3-triazolo[4,5-b] pyridinium 3-oxid hexafluorophosphate, HATU; Triethylamine, TEA ; r.t.: room temperature.
\end{abstract}




\section{Introduction}

Enterovirus 71 (EV71) belongs to Picornaviridae [1] and is the major causative agent in outbreaks of hand, foot and mouth disease (HFMD) in China and Southeastern Asian countries in recent years $[2,3]$. Up to date, there is neither specific antiviral therapy nor vaccine available for the treatment and prevention of EV71 infection.

EV71 is an icosahedral virus with a single stranded and positive sense RNA genome. After entry to cell, its replication starts with the translation of a polyprotein precursor from the monocistronic genome, which is subsequently processed into mature proteins by the virally encoded $2 \mathrm{~A}$ and $3 \mathrm{C}$ proteinases $[4,5] .3 \mathrm{C}$ proteinase $\left(3 \mathrm{C}^{\mathrm{pro}}\right)$ is a cysteine protease with the chymotrypsin-like fold and responsible for all but one of the proteolytic processes. $3 \mathrm{C}^{\text {pro }}$ also plays crucial roles in evading and suppressing the host defense mechanisms $[6,7]$. The essential roles in the life cycle of EV71 and other enteroviruses make $3 \mathrm{C}^{\text {pro }}$ a highly valued therapeutic target. However, no specific drug has been made available up to date targeting $3 \mathrm{C}^{\text {pro }}$ for the treatment and control of the associated diseases.

Significant investment was made to develop rupintrivir (AG7088) as a $3 C^{\text {pro }}$ inhibitor to treat infections by human rhinoviruses (HRV) (Figure 1A) [8]. It is a peptidomimetic with an $\alpha, \beta$-unsaturated ester, or Michael acceptor, for covalent linkage to the nucleophilic sulfur atom of Cys147 in the catalytic triad of $3 \mathrm{C}^{\mathrm{pro}}$. However, due to unfavorable bioavailability and limited efficacy in the treatment of common cold [9], rupintrivir did not pass Phase II in clinical trials. Despite this, rupintrivir is still a highly 
potent compound towards EV71 $3 \mathrm{C}^{\text {pro }}$ in enzymatic and cell-based assays [5]. If its bioavailability can be improved, a new compound with the similar mode of interaction with the proteinase can be a potent drug candidate for treating HFMD.

Modification around one of the peptide bonds in rupintrivir with pyridone helped to increase the stability of the compound, indicating that a possible source of poor bioavailability for rupintrivir is the susceptibility of its two peptide bonds to degradation in plasma [10]. A strategy for developing a more druggable compound is to generate non-peptidomimetics by replacing the two peptide bonds in rupintrivir in a sequential manner with mimics that can maintain or even strengthen the interaction with the enzyme. As such, it is important to understand the contribution of each adduct to the compound potency. Here, a series of peptidomimetic $\alpha, \beta$-unsaturated ester compounds of various lengths was generated and evaluated for their inhibition of EV71 $3 \mathrm{C}^{\text {pro }}$ by structure-based methods. The P2 moiety of the compound would need to be oriented to interact with the S2 site in the substrate binding cleft and the P3-P4 moieties would be required to generate sufficient potency. A hydrophobic terminal group will benefit the cellular uptake and improve the activity in vivo. The effort leads to a better understanding of compound interactions with the enzyme and provides the basis for designing a new generation of inhibitors to target EV71 3C $\mathrm{C}^{\text {pro }}$.

\section{Materials and methods}

\subsection{Chemical synthesis}


Reagents and solvents were obtained from commercial suppliers and were used without further purification. ${ }^{1} \mathrm{H}$ NMR measurements were recorded on a $400 \mathrm{MHz}$ Bruker AMX400 instrument. Compounds were purified by chromatography with silica gel (300-400 mesh) or by RP-HPLC using 10-90\% acetonitrile in $0.1 \%$ aqueous TFA as the gradient and established by LC/MS and NMR. The purities were $>95 \%$ for the final products. The synthetic schemes and procedures are described in Supporting Information.

\subsection{Protein preparation and crystallization}

The expression and purification of EV71 $3 \mathrm{C}^{\mathrm{pro}}$ was carried out as described previously [5]. Briefly, the construct of EV71 (strain E2004104-TW-CDC) 3C pro with carboxy-terminal $6 \times \mathrm{His}$ tag was generated using pET28a vector (Novagen) and overexpressed in E.coli strain BL21(DE3) at $293 \mathrm{~K}$. The recombinant protein was purified by nickel-affinity chromatography followed by DEAE chromatography. The purified EV71 3C $\mathrm{C}^{\mathrm{pro}}$ was incubated with inhibitors at a molar ratio of 1:5 overnight. The crystallization was carried out by the method of hanging-drop vapor diffusion with a reservoir solution of $0.1 \mathrm{M}$ Tris-HCl, $\mathrm{pH} 8.5,25 \%$ PEG4000, and $0.8 \mathrm{M} \mathrm{LiCl}$.

\subsection{Data collection and structure determination}

The crystals were flash cooled to $100 \mathrm{~K}$ for data collection. The X-ray diffraction data for the complexes with Compounds $\mathbf{2}$ and $\mathbf{7}$ were collected at Beamline BL17U1 at Shanghai Synchrotron Radiation Facility (SSRF) with an ADSC Quantum 315r CCD 
detector and processed with HKL2000 [11]. The data for complexes with Compounds 3, 4, 5, 6, 8, and 9 were collected with an in-house Rigaku X-ray generator $\left(\right.$ MicroMax $^{\mathrm{TM}}$ $007 \mathrm{HF}$ ) and Mar345dtb detector. The data were processed with the automar package from the Marresearch $\mathrm{GmbH}$.

The complex structures were determined by molecular replacement with the EV71 $3 \mathrm{C}^{\text {pro }}$ structure (PDB ID: 4GHQ) as the search model by using the program Phaser [12]. Manual model building and refinement were carried out with Coot [13] and Refmac5 [14-16]. The library files for the inhibitors were generated by the program Jligand [17]. The presentations for the crystal structures were generated by PyMOL (Schrödinger).

The coordinates for the complex structures were deposited in Protein Data Bank under the following accession codes: (1) 5DP3, 3C $\mathrm{C}^{\text {ro }}$ in complex with Compound 2; (2) 5DP4, $3 C^{\text {pro }}$ in complex with with Compound 3; (3) 5DP5, 3C ${ }^{\text {pro }}$ in complex with Compound 4; (4) 5DP7, $3 \mathrm{C}^{\text {pro }}$ in complex with Compound 5; (5) 5DPA, $3 \mathrm{C}^{\text {pro }}$ in complex with Compound 6; (6) 5DP6, 3C ${ }^{\text {pro }}$ in complex with Compound 7; (7) 5DP8, 3C ${ }^{\text {pro }}$ in complex with Compound 8; (8) 5DP9, 3C ${ }^{\text {pro }}$ in complex with Compound 9.

\subsection{Enzymatic inhibition and cell-based inhibition assays}

The enzymatic inhibition and cell-based inhibition assays were carried out as described previously [5]. Briefly, the peptide derived from the $3 \mathrm{~B} / 3 \mathrm{C}$ junction in the EV71 precursor polyprotein with a FRET pair (sequence: Dacyl-KRTATVQGPSLDFE-Edans) (the cleavage site between between $\mathrm{Q}$ and $\mathrm{G}$ is indicated with an arrow) was used as 
substrate for the enzymatic activity assay. The cleavage was monitored with the Cary Eclipse Fluorescence Spectrophotometer (Varian) with the excitation wavelength of 340 $\mathrm{nm}$ and emission wavelength of $495 \mathrm{~nm}$. For cell-based activity assay, the EV71 virus and the chemical compounds in DMSO were added to the human embryonic rhabdomyosarcoma cells. CCK-8 was added at the end of incubation to determine the cell viability. The values of $\mathrm{IC}_{50}$ and $\mathrm{EC}_{50}$ were calculated with the Graphpad Prism 5 computer program.

\section{Results}

3.1 The molecular features around the active site of $3 C^{\text {pro }}$ do not provide sufficient constraint for high-affinity and non-covalent interaction

The crystal structure of EV71 3C $\mathrm{C}^{\text {pro }}$ [5] shows that the substrate-binding cleft of the enzyme is wide and shallow. Unlike that in EV71 $2 \mathrm{~A}^{\text {pro }}[18]$, the $\beta$-ribbon on the north side of the substrate binding cleft does not cover over the S2 site, which makes the substrate binding cleft fully solvent-accessible. This is adverse for the binding of non-covalent inhibitors to the cleft, as it not only provides insufficient constraint but also weakens hydrogen bonding or hydrophobic interactions between a binder and the enzyme. As such, a covalent interaction with the active site of the enzyme would be necessary to form an efficient and tight binding.

3.2 Michael acceptor with the S1 interacting moiety is of low potency 
Rupintrivir (Figure 1A), an $\alpha, \beta$-unsaturated ester compound designed for HRV $3 \mathrm{C}^{\mathrm{pro}}$, also inhibits EV71 3C ${ }^{\text {pro }}$ with great potency [5]. It is a peptidomimetic with a Michael acceptor as the warhead and interacts at the S1-S4 sites in the substrate-binding cleft (Figure 1B) [5]. It is conceivable that non-peptidomimetics can be with better bioavailability, which can be generated by replacing the peptide bonds while keeping the essential Michael acceptor. The smallest fragment without the peptide bond contains the Michael acceptor and the P1 (lactam) moiety (Compound 1). Despite the importance of covalent attachment, Compound $\mathbf{1}$ inhibited only $2.56 \%$ of the EV71 $3 \mathrm{C}^{\text {pro }}$ activity at a concentration of $100 \mu \mathrm{M}$ (Table 1). The extension of Compound 1 with the addition of an P2 group in Compound $\mathbf{2}$ did not show any improvement and the potency for Compound 2 was measured as $5.10 \%$ inhibition at a concentration of $100 \mu \mathrm{M}$ (Table 1).

Figure 1 The complex structures between rupintrivir, Compounds 2 and $\mathbf{3}$ with EV71 3C $\mathrm{C}^{\mathrm{pro}}$. (A) The structure of rupintrivir. P1 moiety is for interaction at S1; P2 is for S2, etc. (B) Schematic diagram of the interactions between rupintrivir and EV71 3C pro [5]. (C-D) The complex structure between EV71 $3 \mathrm{C}^{\text {pro }}$ and Compound 2. There was only electron density for the covalent attachment and the lactam moiety at the S1 site (Figure S1B). The P2 group was not visible. (E-F) The complex structure of EV71 $3 C^{\text {Pro }}$ with compound 3. A methyl group although not interacting directly with the enzyme helped to orient the P2 moiety for better interaction at the S2 site.

Table 1 Compound structures, synthesis, $\mathrm{IC}_{50}$ and $\mathrm{EC}_{50}$. 
The complex structure between Compound 2 and EV71 $3 C^{\text {pro }}$ was determined to 2.05 $\AA$ resolution (Figure 1C, Table 2). The protein structures were with an r.m.s.d. of $0.33 \AA$ for all the $\mathrm{C} \alpha$ atoms between the apo protein and complex. The active, $\mathrm{S} 1$ and $\mathrm{S} 2$ sites are in a basin-like structure [5], which is of little non-covalent constraint to the interacting compound (Figure 1C). Besides two hydrogen bonds between the lactam moiety (P1) of the compound and His161 and Thr142 of the enzyme, the covalent attachment is the only major interaction for the compound attachment to the active site (Figure 1D, Table S1). The P2 moiety intending to interact at the S2 site was completely not visible in the complex structure so the electron density was essentially a fit for Compound $\mathbf{1}$ (Figure S1B), thereby explaining the lack of improvement on the potency of Compound 2 over that of Compound $\mathbf{1}$.

Table 2 Data collection and refinement statistics.

\subsection{P2 needs to be oriented}

A measurable improvement can be demonstrated with the addition of a methyl group to the terminus of Compound $\mathbf{2}$ in Compound $\mathbf{3}$ (Table 1). Although this additional methyl group is not long enough to reach the $\mathrm{S} 3$ site of the substrate-binding cleft, Compound 3 has an $\mathrm{IC}_{50}$ of $62.88 \mu \mathrm{M}$ (Table 1). To understand the role of the terminal methyl group, the complex structure with Compound $\mathbf{3}$ was characterized to $2.21 \AA$ resolution (Figure 
1E, Table 2). Although the methyl group was with no obvious interaction with the enzyme, its presence allows the P2 group to interact at S2 with the benzene ring fitting snugly in the pocket formed with Glu71 and His40. This orientation of P2 was also accompanied with additional interactions at S1' between the Michael acceptor and the main chain amide from Gly145, as well as a hydrogen bonding interaction from a mainchain nitrogen atom with the sidechain of Cys147 and the mainchain oxygen atom of Ile162 (Table S1).

\subsection{Improve the potency with interaction at $S 3$}

It can be demonstrated that the potency can be further improved if the interactions were introduced at the S3 site. The introduction of an isopropyl group and a terminal amine in Compound 4 generates a new hydrogen bond at the S3 site with Gly164 (Figure 2AB and Figure S1D) with an additional hydrogen bond with Arg39 at the S2 site (Table S1). As a consequence of the improved interaction, $\mathrm{IC}_{50}$ value was now at $18.70 \mu \mathrm{M}$ (Table 1 ). However, its $\mathrm{EC}_{50}$ value was still not favorable at over $100 \mu \mathrm{M}$, indicating that the hydrophobicity might still need to be adjusted to favor the cellular uptake.

Figure 2 Introduction of interactions at the S3 site improve the potency. (A-B) The complex structure with compound 4. The isopropyl and amide groups form a hydrogen with Gly164 at S3. A hydrogen bond was also formed between the fluoro atom in P2 and Arg39. (C-D) The complex structure with compound 5. The isopropyl group is linked with a peptide bond. The peptide bond forms two 
hydrogen bonds with Gly164 and the P3 group could reach the S3 site but does not seem to form any specific interaction; (E-F) The complex structure with compound 6. Compounds $\mathbf{6}$ adopts similar pose in the substrate-binding cleft of $3 C^{\text {pro }}$ as Compound 5 does.

Although the terminal amine forms a hydrogen bond with Gly164, it orients the isopropyl group away from the $\mathrm{S} 4$ site in Compound 4. Also taking account of its hydrophilicity, this terminal amine was eliminated in Compound 5. For the convenience of synthesis, a peptide bond was used to link the P2 and P3 moieties. In the complex structure between EV71 $3 \mathrm{C}^{\text {pro }}$ and Compound 5 (Figure 2CD and Figure S1E), the peptide bond between P2 and P3 moieties generates two hydrogen bonds with Ser128, which makes up the lost hydrogen bond between the terminal amine and the carbonyl oxygen of Gly164 as in Compound 4 (Table S1). This indicates that the interaction in the main chain should be taken into consideration in the future replacement of peptide bonds. The isopropyl group in Compound 5 is now oriented towards the S4 site (Figure 2CD), which is another factor to be considered in the replacement of the peptide bonds. The $\mathrm{IC}_{50}$ value of Compound 5 though was not better $(27.57 \mu \mathrm{M}$, Table 1$)$, despite the apparent formation of new interactions, but the placement of a terminal hydrophobic group seemed to be helpful in lowering the $\mathrm{EC}_{50}$ value over that of Compound 4 (Table 1).

To demonstrate the importance of hydrophobicity in the terminal group, the isopropyl group in Compound 5 was reduced to a methyl group to generate Compound $\mathbf{6}$. The complex structure (Figure 2EF and Figure S1F) shows that the Compounds 5 and $\mathbf{6}$ adopt 
similar pose in the substrate-binding cleft of $3 \mathrm{C}^{\mathrm{pro}}$. The $\mathrm{IC}_{50}$ of Compound $\mathbf{6}$ is $22.46 \mu \mathrm{M}$, at the same level with Compounds $\mathbf{4}$ and $\mathbf{5}$, but the $\mathrm{EC}_{50}$ value is more like that of Compound 4, implicating the importance of introducing hydrophobicity in the terminal group of the compound for improving the cellular uptake.

\subsection{Interactions at $S 4$}

The complex structures with Compounds $\mathbf{4 , 5}$, and $\mathbf{6}$ show limited interaction at S4 and the potency for each of them is moderate. As the S4 site looks mostly hydrophobic, it should be able to accommodate a larger non-polar group for better interaction and higher hydrophobicity. Compound 7 was generated with the replacement of the isopropyl group in Compound 5 with a larger cyclopropylpropanyl moiety for interaction at the S4 site (Table 1). The complex structure with Compound 7 showed that the hydrogen-bonding interactions with EV71 $3 C^{\text {pro }}$ is similar to that of Compound 5 (Figure 3AB, Figure S1G and Table S1) but the larger cyclopropylpropanyl moiety did not generate additional specific interaction, despite the fact that it has reached the S4 site. No significant improvement was observed for either the $\mathrm{IC}_{50}$ value $(14.71 \mu \mathrm{M}$, Table 1$)$ or the $\mathrm{EC}_{50}$ value (31.93 $\mu \mathrm{M}$, Table 1$)$. It seems that improvement over both specific interaction and hydrophobicity would be needed to generate better inhibitors to $3 \mathrm{C}^{\text {pro }}$. We installed a reverse peptide bond in addition to hydrophobic components in Compounds $\mathbf{8}$ and $\mathbf{9}$, one with a cyclopropylethyl group and the other with cyclobutylmethyl group which lead to significant improvements in both $\mathrm{IC}_{50}$ values and $\mathrm{EC}_{50}$ values (Table 1). In the complex 
structures, both compounds are long enough to reach the S4 site (Figure 3CD, Figure 3EF, Figure S1H and Figure S1I). More importantly, the reverse peptide bonds afford additional hydrogen bonds with Gly164, consistent with the lower $\mathrm{IC}_{50}$ values. The improved $\mathrm{EC}_{50}$ values are attributed to the introduction of hydrophobic components at the termini.

Figure 3 Interactions at the S4 site. (A-B) The complex structure with compound 7. Although the terminal group can reach the S4 site, it does not seem to generate any specific interaction. (C-D) The complex structure with compound 8. The compound is with a reverse peptide bond and a cyclopropylethyl terminal group; (E-F) The complex structure with compound $\mathbf{9}$. A reverse peptide is introduced, as that in Compound $\mathbf{8}$, and a cyclobutylmethyl terminal group is installed. The reverse peptide bond generates additional hydrogen bonds with Gly164. The hydrophobic components were attributed to the better $\mathrm{EC}_{50}$ values.

\section{Discussion}

$3 \mathrm{C}^{\mathrm{pro}}$ is an important drug target for treating infections by enteroviruses, HRV, and other picornaviruses. Various compounds, mostly peptidomimetics, were developed targeting the enzyme with warheads, such as $\alpha, \beta$-unsaturated esters, for attacking the catalytic Cys residue [8, 10, 21-27]. A general problem for these peptidomimetcs, such as rupintrivir, is their low bioavailability. Up to now, two sources of low bioavailability can be identified. One is the vulnerability of the warhead to hydrolysis $[24,28]$, and the other 
is the susceptibility of their peptide bonds to degradation [10].

Modification of one of the peptide bonds in rupintrivir with pyridone resulted in improving the stability of the compound and it would be of great interest to replace both peptide bonds with protease-resistant mimics. However, not only do these peptide bonds participate in direct H-bonding interactions with the enzyme, they are also part of the scaffold that provides the essential framework for these compounds to fit in the substrate-binding cleft. As such, these peptide bonds cannot be replaced in a straightforward manner. The production of next generation of anti-3C $\mathrm{C}^{\text {pro }}$ compounds might have to take the route of sequential replacement of the peptide bonds from the warhead based on the detailed understanding of the interactions between various components of the peptidomimetics and the enzyme.

In this work, we used lactam with an $\alpha, \beta$-unsaturated ester, the largest fragment without a peptide bond in rupintrivir, as the starting material to generate a series of compounds with different length to investigate the contribution of each adduct to the potency. Despite the highly active Michael acceptor moiety, the inhibiting power of Compound $\mathbf{1}$ is not of sufficient inhibition to the enzyme activity. An adduct with an S2-interacting moiety is not of much contribution to the activity and the potency of compound $\mathbf{2}$ was basically that for compound $\mathbf{1}$. The complex structure with compound $\mathbf{2}$ showed a compound binding in essentially the same pose as the complex with compound 1 as the additional component linked by a peptide bond to the compound 1 was not detectable in the complex structure. The lack of detectable density for the connecting 
peptide bond and benzene group in compound $\mathbf{2}$ also indicated that the substrate-binding cleft did not provide sufficient constraint for binding the peptide bond and the P2 moiety. This peptide bond can be replaced with a chemical component that can orient the P2 moiety for binding at the S2 site. As the peptide bond itself could contribute to the direct interaction with the enzyme [5], a peptide bond mimic, such as a 1,4-disubstituted [1-3] triazole $[29,30]$, might be preferred.

The orientation of $\mathrm{P} 2$ to bind at the $\mathrm{S} 2$ site could be achieved by adding a methyl group to compound 2 with a favorable enhancement to the potency. In the complex structure with compound $\mathbf{3}$, the methyl group itself did not seem to interact with any part of the enzyme, but to orient the P2 moiety for interaction at the S2 site.

Introduction of additional interaction around the S3 site would confer the compound with additional affinities and the sufficient potency could be achieved by installing S4 interacting groups. The fact that a $\mathrm{P} 4$ group could generate favorable interactions even if it was linked with a reverse peptide bond is an indication that a potent and non-peptidomimetic anti-3 $\mathrm{C}^{\text {pro }}$ compound can be generated when a suitable substitute was employed. Our data also show that it is necessary to install a hydrophobic group as the terminal group in an anti-3C $\mathrm{C}^{\text {pro }}$ compound for enhanced cellular uptake.

\section{Conclusions}

$3 \mathrm{C}^{\text {pro }}$ is an important drug target for treating HFMD. Despite extensive efforts, no specific therapeutics has reached clinical application. A source of the problem is the low 
plasma stability of peptidomimetic inhibitors developed up to date. In order to generate compounds with better bioavailability, an understanding on the contribution of constituent components would be helpful for the replacement of peptide bonds in peptidomimetics. By structure-based methods, a series of compounds in different length was generated. The revelation of the interacting modes in conjunction with the compound potency provides the basis for designing a new generation of non-peptidomimetics to target EV71 3C

\section{Acknowledgments}

The research was supported by the funding from National Basic Research Program of China (973 program, 2012CB724500), from the Open Research Fund of the State Key Laboratory of Cellular Stress Biology, Xiamen University (SKLCSB2012KF003), from the 111 Project of Education of China (B06016), from the National Science Foundation of China for Fostering Talents in Basic Research (J1310027), and from China Postdoctoral

Science Foundation (2014T70604). The crystallographic data collection at Beamline BL17U1 at Shanghai Synchrotron Radiation Facility is gratefully acknowledged.

\section{Conflict of interest statement}

The authors declare no competing financial interests. 


\section{References}

[1] V.R. Racaniello, Picornavirdae: the viruses and their replication, In Fields Virology, Lippincott Williams \& Wilkins Publishers, 2006, pp. p. 795.

[2] C.C.f.D.C.a.P.a.O.o.t.W.H.O.i. China, Report on the hand, foot and mouth disease outbreak in Fuyang city, Anhui Province and the prevention and control in China., in, 2008.

[3] F. Yang, L. Ren, Z. Xiong, J. Li, Y. Xiao, R. Zhao, Y. He, G. Bu, S. Zhou, J. Wang, J. Qi, Enterovirus 71 outbreak in the People's Republic of China in 2008, J Clin Microbiol, 47 (2009) 2351-2352.

[4] S. Cui, J. Wang, T. Fan, B. Qin, L. Guo, X. Lei, J. Wang, M. Wang, Q. Jin, Crystal structure of human enterovirus 71 3C protease, J Mol Biol, 408 (2011) 449-461.

[5] C. Wu, Q. Cai, C. Chen, N. Li, X. Peng, Y. Cai, K. Yin, X. Chen, X. Wang, R. Zhang, L. Liu, S. Chen, J. Li, T. Lin, Structures of Enterovirus 71 3C proteinase (strain E2004104-TW-CDC) and its complex with rupintrivir, Acta Crystallogr D Biol Crystallogr, 69 (2013) 866-871.

[6] K.F. Weng, M.L. Li, C.T. Hung, S.R. Shih, Enterovirus 71 3C protease cleaves a novel target CstF-64 and inhibits cellular polyadenylation, PLoS Pathog, 5 (2009) e1000593.

[7] Y. Yang, Y. Liang, L. Qu, Z. Chen, M. Yi, K. Li, S.M. Lemon, Disruption of innate immunity due to mitochondrial targeting of a picornaviral protease precursor, Proc Natl Acad Sci U S A, 104 (2007) 7253-7258.

[8] D.A. Matthews, P.S. Dragovich, S.E. Webber, S.A. Fuhrman, A.K. Patick, L.S. Zalman, T.F. Hendrickson, R.A. Love, T.J. Prins, J.T. Marakovits, R. Zhou, J. Tikhe, C.E. Ford, J.W. Meador, R.A. Ferre, E.L. Brown, S.L. Binford, M.A. Brothers, D.M. DeLisle, S.T. Worland, 
Structure-assisted design of mechanism-based irreversible inhibitors of human rhinovirus 3C protease with potent antiviral activity against multiple rhinovirus serotypes, Proc Natl Acad Sci U S A, 96 (1999) 11000-11007.

[9] F.G. Hayden, R.B. Turner, J.M. Gwaltney, K. Chi-Burris, M. Gersten, P. Hsyu, A.K. Patick, G.J. Smith, 3rd, L.S. Zalman, Phase II, randomized, double-blind, placebo-controlled studies of ruprintrivir nasal spray 2-percent suspension for prevention and treatment of experimentally induced rhinovirus colds in healthy volunteers, Antimicrob Agents Chemother, 47 (2003) 3907-3916.

[10] P.S. Dragovich, T.J. Prins, R. Zhou, E.L. Brown, F.C. Maldonado, S.A. Fuhrman, L.S. Zalman, T. Tuntland, C.A. Lee, A.K. Patick, D.A. Matthews, T.F. Hendrickson, M.B. Kosa, B. Liu, M.R. Batugo, J.P. Gleeson, S.K. Sakata, L. Chen, M.C. Guzman, J.W. Meador, 3rd, R.A. Ferre, S.T. Worland, Structure-based design, synthesis, and biological evaluation of irreversible human rhinovirus 3C protease inhibitors. 6. Structure-activity studies of orally bioavailable, 2-pyridone-containing peptidomimetics, J Med Chem, 45 (2002) 1607-1623.

[11] Z.a.M. Otwinowski, W, Processing of X-ray Diffraction Data Collected in Oscillation Mode, Methods Enzymol, 276 (1997) 307-326.

[12] A.J. McCoy, R.W. Grosse-Kunstleve, P.D. Adams, M.D. Winn, L.C. Storoni, R.J. Read, Phaser crystallographic software, J Appl Crystallogr, 40 (2007) 658-674.

[13] P. Emsley, B. Lohkamp, W.G. Scott, K. Cowtan, Features and development of Coot, Acta Crystallogr D Biol Crystallogr, 66 (2010) 486-501.

[14] G.N. Murshudov, P. Skubak, A.A. Lebedev, N.S. Pannu, R.A. Steiner, R.A. Nicholls, M.D. Winn, 
F. Long, A.A. Vagin, REFMAC5 for the refinement of macromolecular crystal structures, Acta Crystallogr D Biol Crystallogr, 67 (2011) 355-367.

[15] G.N. Murshudov, A.A. Vagin, E.J. Dodson, Refinement of macromolecular structures by the maximum-likelihood method, Acta Crystallogr D Biol Crystallogr, 53 (1997) 240-255.

[16] M.D. Winn, C.C. Ballard, K.D. Cowtan, E.J. Dodson, P. Emsley, P.R. Evans, R.M. Keegan, E.B. Krissinel, A.G. Leslie, A. McCoy, S.J. McNicholas, G.N. Murshudov, N.S. Pannu, E.A. Potterton, H.R. Powell, R.J. Read, A. Vagin, K.S. Wilson, Overview of the CCP4 suite and current developments, Acta Crystallogr D Biol Crystallogr, 67 (2011) 235-242.

[17] A.A. Lebedev, P. Young, M.N. Isupov, O.V. Moroz, A.A. Vagin, G.N. Murshudov, JLigand: a graphical tool for the CCP4 template-restraint library, Acta Crystallogr D Biol Crystallogr, 68 (2012) 431-440.

[18] Q. Cai, M. Yameen, W. Liu, Z. Gao, Y. Li, X. Peng, Y. Cai, C. Wu, Q. Zheng, J. Li, T. Lin, Conformational plasticity of the 2A proteinase from enterovirus 71, J Virol, 87 (2013) 7348-7356.

[19] T.O.J. P.S. Dragovich, T.J. Prins, R. Zhou, Antipicornaviral compounds and compositions, their pharmaceutical uses, and materials for their synthesis, in: Google Patents, 2001.

[20] D.W. Ma, Xie, W. Q., Zou, B., Lei, Q. and Pei, D. Q., An efficient and tunable route to AG7088, a rhinovirus protease inhibitor., Tetrahedron Letters, 45 (2004) 8103-8105.

[21] P.S. Dragovich, S.E. Webber, R.E. Babine, S.A. Fuhrman, A.K. Patick, D.A. Matthews, C.A. Lee, S.H. Reich, T.J. Prins, J.T. Marakovits, E.S. Littlefield, R. Zhou, J. Tikhe, C.E. Ford, M.B. Wallace, J.W. Meador, 3rd, R.A. Ferre, E.L. Brown, S.L. Binford, J.E. Harr, D.M. DeLisle, S.T. Worland, Structure-based design, synthesis, and biological evaluation of irreversible human 
rhinovirus 3C protease inhibitors. 1. Michael acceptor structure-activity studies, J Med Chem, 41 (1998) 2806-2818.

[22] P.S. Dragovich, S.E. Webber, R.E. Babine, S.A. Fuhrman, A.K. Patick, D.A. Matthews, S.H. Reich, J.T. Marakovits, T.J. Prins, R. Zhou, J. Tikhe, E.S. Littlefield, T.M. Bleckman, M.B. Wallace, T.L. Little, C.E. Ford, J.W. Meador, 3rd, R.A. Ferre, E.L. Brown, S.L. Binford, D.M. DeLisle, S.T. Worland, Structure-based design, synthesis, and biological evaluation of irreversible human rhinovirus 3C protease inhibitors. 2. Peptide structure-activity studies, J Med Chem, 41 (1998) 2819-2834.

[23] P.S. Dragovich, T.J. Prins, R. Zhou, S.A. Fuhrman, A.K. Patick, D.A. Matthews, C.E. Ford, J.W. Meador, 3rd, R.A. Ferre, S.T. Worland, Structure-based design, synthesis, and biological evaluation of irreversible human rhinovirus $3 \mathrm{C}$ protease inhibitors. 3. Structure-activity studies of ketomethylene-containing peptidomimetics, J Med Chem, 42 (1999) 1203-1212.

[24] P.S. Dragovich, T.J. Prins, R. Zhou, S.E. Webber, J.T. Marakovits, S.A. Fuhrman, A.K. Patick, D.A. Matthews, C.A. Lee, C.E. Ford, B.J. Burke, P.A. Rejto, T.F. Hendrickson, T. Tuntland, E.L. Brown, J.W. Meador, 3rd, R.A. Ferre, J.E. Harr, M.B. Kosa, S.T. Worland, Structure-based design, synthesis, and biological evaluation of irreversible human rhinovirus 3C protease inhibitors. 4. Incorporation of P1 lactam moieties as L-glutamine replacements, J Med Chem, 42 (1999) 1213-1224.

[25] P.S. Dragovich, T.J. Prins, R. Zhou, T.O. Johnson, Y. Hua, H.T. Luu, S.K. Sakata, E.L. Brown, F.C. Maldonado, T. Tuntland, C.A. Lee, S.A. Fuhrman, L.S. Zalman, A.K. Patick, D.A. Matthews, E.Y. Wu, M. Guo, B.C. Borer, N.K. Nayyar, T. Moran, L. Chen, P.A. Rejto, P.W. Rose, 
M.C. Guzman, E.Z. Dovalsantos, S. Lee, K. McGee, M. Mohajeri, A. Liese, J. Tao, M.B. Kosa, B. Liu, M.R. Batugo, J.P. Gleeson, Z.P. Wu, J. Liu, J.W. Meador, 3rd, R.A. Ferre, Structure-based design, synthesis, and biological evaluation of irreversible human rhinovirus $3 \mathrm{C}$ protease inhibitors. 8. Pharmacological optimization of orally bioavailable 2-pyridone-containing peptidomimetics, J Med Chem, 46 (2003) 4572-4585.

[26] P.S. Dragovich, T.J. Prins, R. Zhou, T.O. Johnson, E.L. Brown, F.C. Maldonado, S.A. Fuhrman, L.S. Zalman, A.K. Patick, D.A. Matthews, X. Hou, J.W. Meador, R.A. Ferre, S.T. Worland, Structure-based design, synthesis, and biological evaluation of irreversible human rhinovirus $3 \mathrm{C}$ protease inhibitors. Part 7: structure-activity studies of bicyclic 2-pyridone-containing peptidomimetics, Bioorg Med Chem Lett, 12 (2002) 733-738.

[27] J. Tan, S. George, Y. Kusov, M. Perbandt, S. Anemuller, J.R. Mesters, H. Norder, B. Coutard, C. Lacroix, P. Leyssen, J. Neyts, R. Hilgenfeld, 3C protease of enterovirus 68: structure-based design of Michael acceptor inhibitors and their broad-spectrum antiviral effects against picornaviruses, J Virol, 87 (2013) 4339-4351.

[28] K.E. Zhang, B. Hee, C.A. Lee, B. Liang, B.C. Potts, Liquid chromatography-mass spectrometry and liquid chromatography-NMR characterization of in vitro metabolites of a potent and irreversible peptidomimetic inhibitor of rhinovirus 3C protease, Drug Metab Dispos, 29 (2001) 729-734.

[29] M. Meldal, C.W. Tornoe, Cu-catalyzed azide-alkyne cycloaddition, Chem Rev, 108 (2008) 2952-3015.

[30] C.W. Tornoe, C. Christensen, M. Meldal, Peptidotriazoles on solid phase: [1,2,3]-triazoles by 
regiospecific copper(i)-catalyzed 1,3-dipolar cycloadditions of terminal alkynes to azides, J Org Chem, 67 (2002) 3057-3064. 
Table 1 Compound structures, synthesis, $\mathrm{IC}_{50}$ and $\mathrm{EC}_{50}$.

\begin{tabular}{|c|c|c|c|}
\hline ID $\left(\right.$ method $\left.^{\mathrm{a}}\right)$ & Chemical structure & $\mathrm{IC}_{50}(\mu \mathrm{M})^{\mathrm{b}}$ & $\mathrm{EC}_{50}(\mu \mathrm{M})^{\mathrm{c}}$ \\
\hline Rupintrivir & & 1.67 & 0.041 \\
\hline Compound 1 [19] & & $\begin{array}{l}2.56 \% \\
(\text { at } 100 u M)^{d}\end{array}$ & $>100$ \\
\hline Compound 2 (A) & & $\begin{array}{l}5.01 \% \\
(\text { at } 100 \mu \mathrm{M})^{\mathrm{d}}\end{array}$ & $>100$ \\
\hline Compound $\mathbf{3}$ (A) & & 62.88 & $>100$ \\
\hline Compound 4 [20] & & 18.70 & $>100$ \\
\hline Compound 5 (B) & & 27.57 & 33.33 \\
\hline
\end{tabular}


Compound 6 (A)

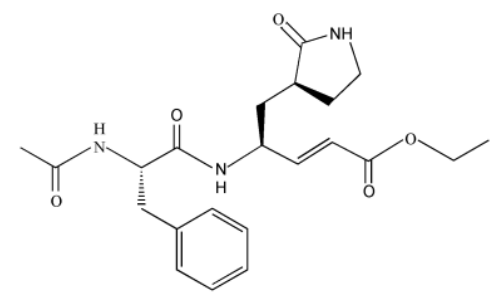

Compound 7 (B)<smiles>CCOC(=O)/C=C/[C@H](C[C@@H]1CCNC1=O)NC(=O)[C@H](Cc1ccccc1)NC(=O)CCC1CC1</smiles>

Compound 8 (C)<smiles>CCOC(=O)/C=C/[C@H](C[C@@H]1CCNC1=O)NC(=O)[C@H](Cc1ccccc1)NC(=O)C(=O)NCCC1CC1</smiles>

Compound 9 (C)

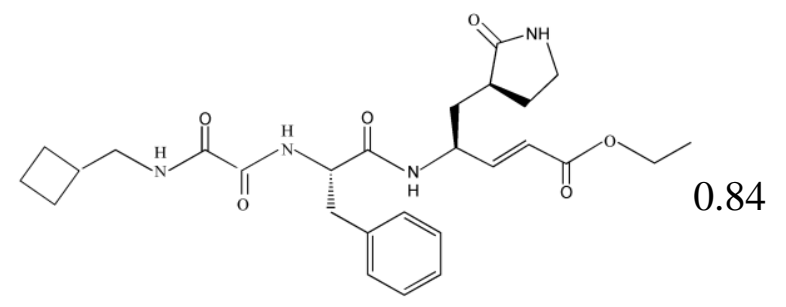

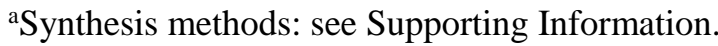

${ }^{\mathrm{b}} \mathrm{IC}_{50}$ : measure of the effectiveness of a substance in inhibiting a specific biological or biochemical function.

${ }^{c} \mathrm{EC}_{50}$ : measure of the potency of a substance in inducing a response halfway between the baseline and maximum.

${ }^{\mathrm{d}}$ Compounds $1 \& \mathbf{2}$ have different units, because their low $\mathrm{IC}_{50}$ and $\mathrm{EC}_{50}$ values. 
Table 2 Data collection and refinement statistics.

\begin{tabular}{|c|c|c|c|c|c|c|c|c|}
\hline Compound ID & 2 & 3 & 4 & 5 & 6 & 7 & 8 & 9 \\
\hline \multicolumn{9}{|l|}{ Data collection } \\
\hline Space group & $\mathrm{C} 222_{1}$ & $\mathrm{P} 22_{1} 2_{1}$ & $\mathrm{C} 222_{1}$ & $\mathrm{C} 222_{1}$ & $\mathrm{C} 222_{1}$ & $\mathrm{P} 2{ }_{1} 2_{1} 2_{1}$ & $\mathrm{C} 222_{1}$ & $\mathrm{C} 222_{1}$ \\
\hline \multicolumn{9}{|l|}{ Cell } \\
\hline \multicolumn{9}{|l|}{ dimensions } \\
\hline$a(\AA)$ & 64.623 & 63.894 & 64.175 & 64.203 & 63.938 & 85.840 & 63.945 & 64.126 \\
\hline$b(\AA)$ & 64.845 & 75.456 & 64.813 & 65.319 & 65.158 & 85.709 & 64.976 & 65.234 \\
\hline$c(\AA)$ & 75.366 & 128.885 & 76.151 & 76.443 & 75.564 & 101.315 & 75.606 & 76.044 \\
\hline \multirow[t]{2}{*}{ Resolution $(\AA)$} & $50-2.05$ & $50-2.21$ & $50-2.03$ & $50-2.08$ & $50-2.06$ & $50-3.00$ & $50-2.40$ & $50-1.90$ \\
\hline & $(2.09-2.05)$ & $(2.29-2.21)$ & $(2.11-2.03)$ & $(2.15-2.08)$ & $(2.13-2.06)$ & $(3.05-3.00)$ & $(2.49-2.40)$ & $(1.97-1.90)$ \\
\hline $\mathrm{R}_{\text {merge }}(\%)$ & $10.8(44.5)$ & $4.7(14.9)$ & $6.0(13.8)$ & $5.7(23.7)$ & $6.2(40.1)$ & $14.8(87.9)$ & $10.9(28.0)$ & $10.8(40.0)$ \\
\hline $\mathrm{I} / \sigma \mathrm{I}$ & $15.7(4.0)$ & $13.3(4.9)$ & $11.7(4.1)$ & $8.4(2.9)$ & $7.7(2.0)$ & $12.3(1.9)$ & $5.4(1.9)$ & $5.8(0.9)$ \\
\hline Completeness & 98.8 (99.6) & $98.0(88.4)$ & $89.9(82.2)$ & 92.7 (93.9) & $96.5(97.2)$ & $96.7(98.0)$ & $95.8(99.7)$ & 95.8 (96.9) \\
\hline \multicolumn{9}{|l|}{$(\%)$} \\
\hline Redundancy & $4.2(4.0)$ & $6.1(5.2)$ & $2.4(2.4)$ & $2.6(2.6)$ & $4.0(4.0)$ & $4.8(4.9)$ & $3.5(3.7)$ & $3.7(3.7)$ \\
\hline \multicolumn{9}{|l|}{ Refinement } \\
\hline Resolution $(\AA)$ & 2.05 & 2.21 & 2.03 & 2.08 & 2.06 & 3.01 & 2.40 & 1.90 \\
\hline No. reflections & 9647 & 29625 & 8993 & 8789 & 9259 & 731 & 5870 & 11963 \\
\hline \multirow[t]{2}{*}{$R_{\mathrm{work}} / R_{\mathrm{free}}$} & $0.224 / 0.29$ & $0.212 / 0.26$ & $0.220 / 0.29$ & $0.212 / 0.26$ & $0.230 / 0.29$ & $0.229 / 0.27$ & $0.208 / 0.27$ & $0.242 / 0.29$ \\
\hline & 4 & 1 & 0 & 0 & 2 & 9 & 6 & 3 \\
\hline \multicolumn{9}{|l|}{ No. atoms } \\
\hline Protein & 1401 & 5572 & 1393 & 1393 & 1393 & 5553 & 1393 & 1409 \\
\hline Ligand/io & 11 & 108 & 35 & 33 & 30 & 68 & 37 & 37 \\
\hline \multicolumn{9}{|l|}{$\mathrm{n}$} \\
\hline Water & 131 & 363 & 87 & 81 & 78 & 0 & 44 & 134 \\
\hline \multicolumn{9}{|l|}{ B-factors $\left(\AA^{2}\right)$} \\
\hline Protein & 24.9 & 18.5 & 24.1 & 22.2 & 37.3 & $92.1 *$ & 37.5 & 30.0 \\
\hline Ligand/io & 42.8 & 26.8 & 27.1 & 29.2 & 42.7 & 55.1 & 44.7 & 39.7 \\
\hline \multicolumn{9}{|l|}{$\mathrm{n}$} \\
\hline Water & 31.7 & 24.4 & 28.2 & 25.7 & 33.3 & 0 & 30.9 & 37.3 \\
\hline \multicolumn{9}{|c|}{ Ramachandran statistics (\%) } \\
\hline Most favored & 92.13 & 94.27 & 93.85 & 92.18 & 91.06 & 91.67 & 91.62 & 92.09 \\
\hline Allowed & 7.30 & 4.75 & 5.59 & 6.70 & 7.26 & 6.92 & 7.82 & 6.78 \\
\hline Outliers & 0.56 & 0.98 & 0.56 & 1.12 & 1.68 & 1.41 & 0.56 & 1.13 \\
\hline \multicolumn{9}{|l|}{ R.m.s. deviations } \\
\hline $\begin{array}{l}\text { Bond lengths } \\
(\AA)\end{array}$ & 0.016 & 0.017 & 0.015 & 0.016 & 0.014 & 0.015 & 0.012 & 0.010 \\
\hline Bond angles $\left({ }^{\circ}\right)$ & 1.841 & 1.811 & 1.763 & 1.834 & 1.853 & 1.730 & 1.690 & 1.921 \\
\hline
\end{tabular}


Values in parentheses are for highest-resolution shell.

The Ramachandran statistics were calculated by Coot [13].

*There are 4 complex structures for compound 7 in each asymmetric unit cell of the crystal. Two of the structures were with good electron density, while the density for other two were not so defined. As a result, the overall $\mathrm{B}$ factor is high. 


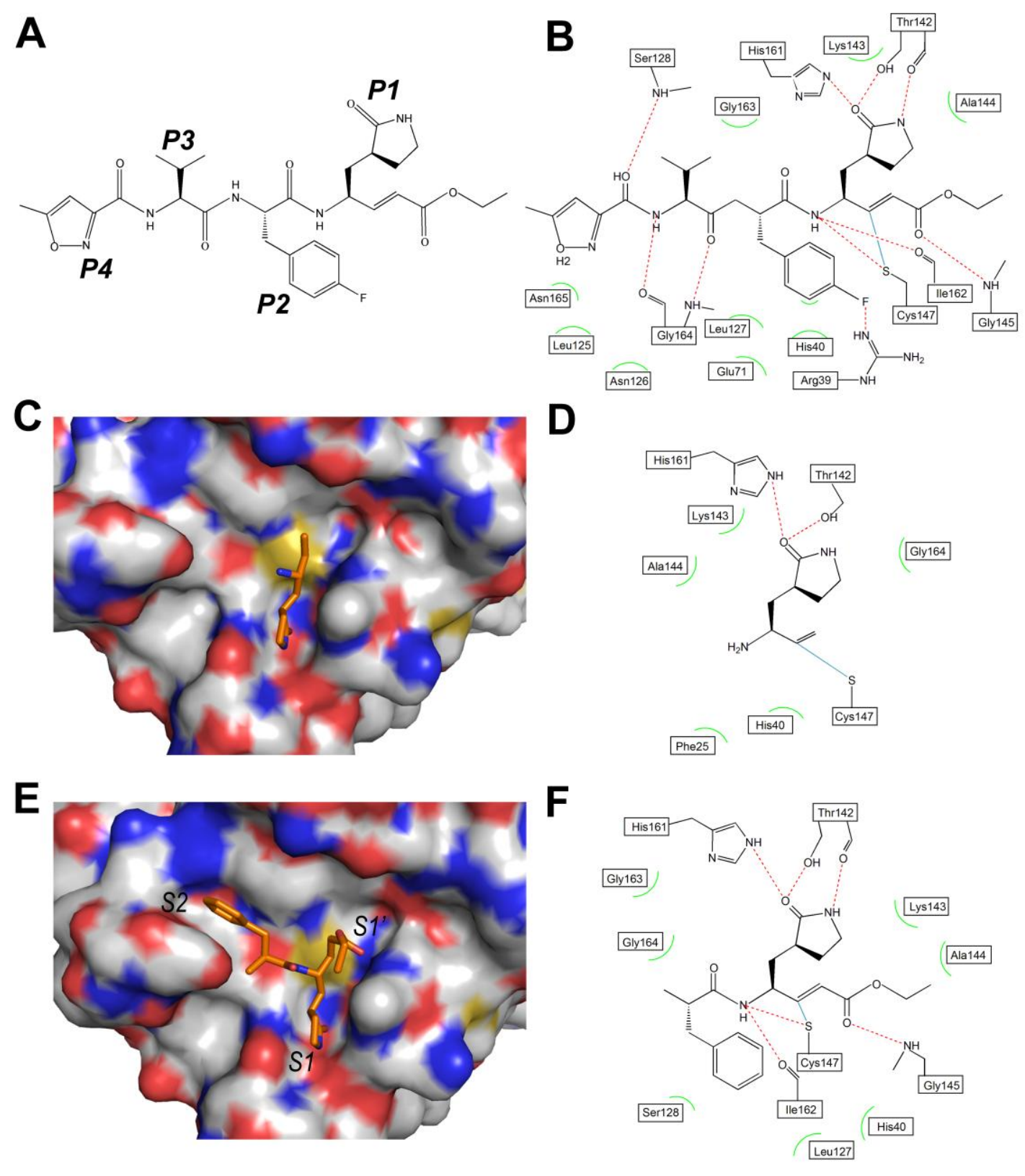


A

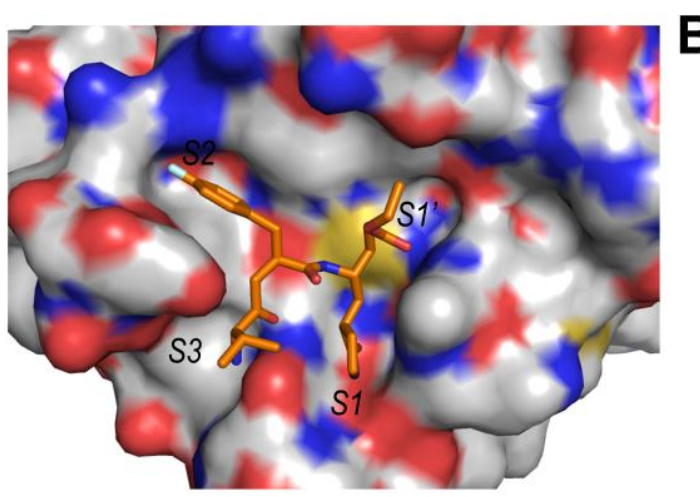

C

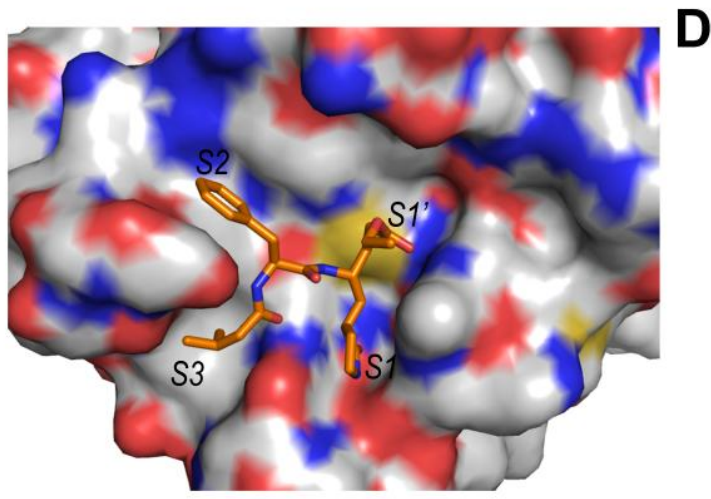

E

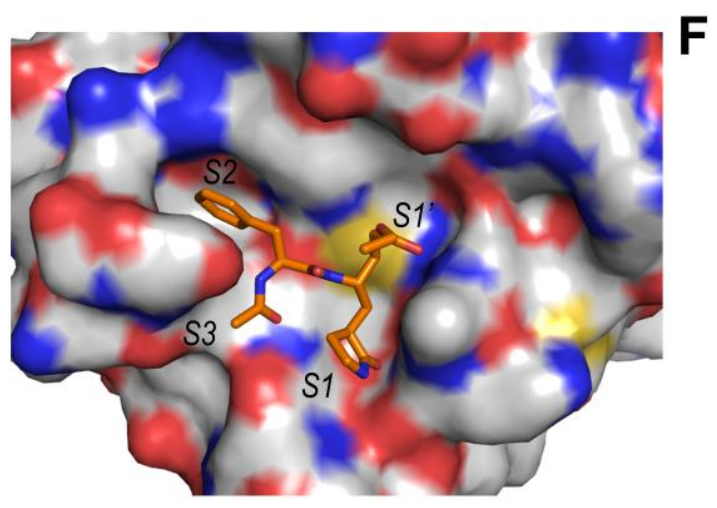

B

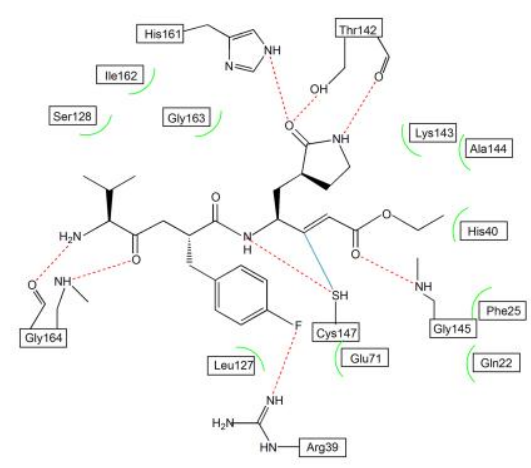

D
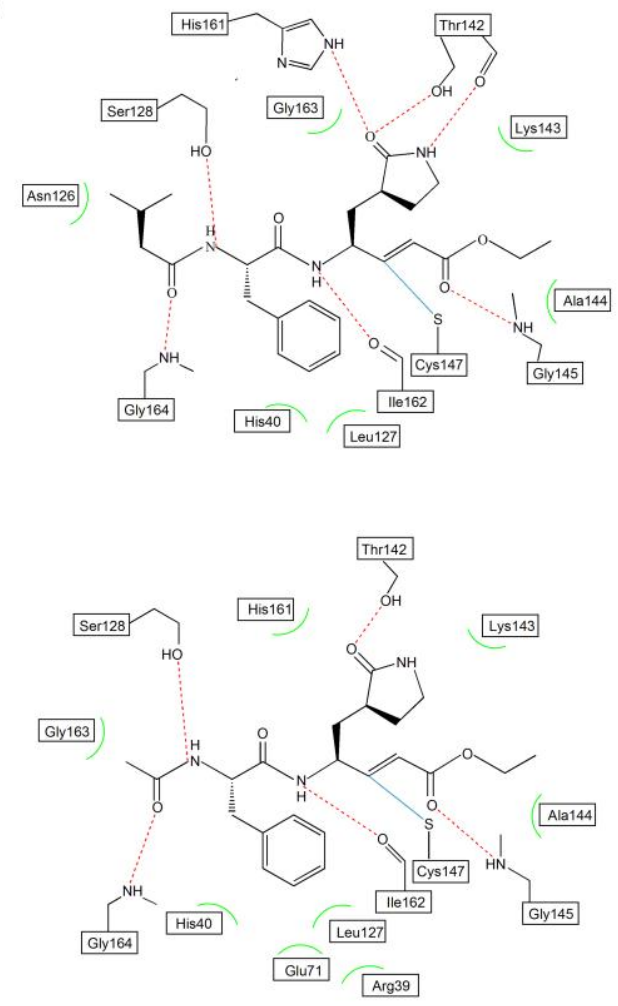

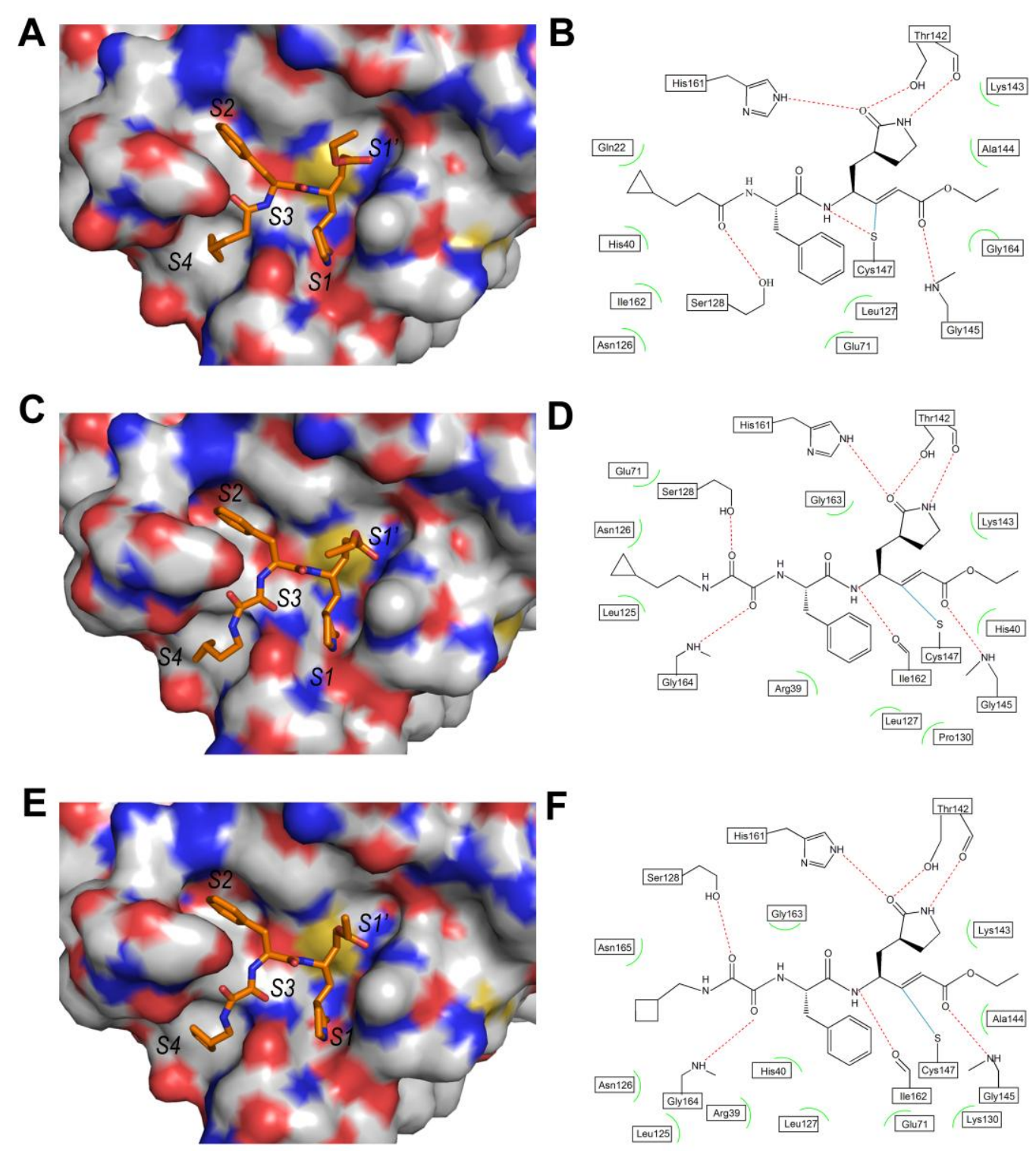
<smiles>[R]C(Cc1ccccc1)C(=O)O</smiles>

1-1a $\quad \mathrm{R}=\mathrm{H}$

1-1b $\mathrm{R}=\mathrm{Me}$

1-1c $\mathrm{R}=\mathrm{AcNH}$

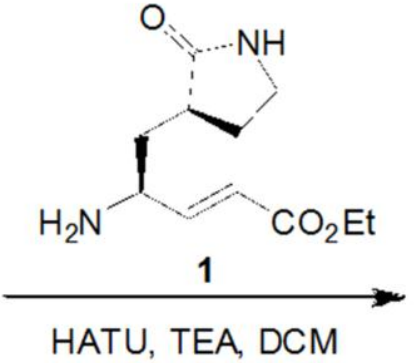

$\mathrm{rt}$, overnight<smiles>[R]C(Cc1ccccc1)C(=O)N[C@@H](/C=C/C(=O)OCC)C[C@H]1CCNC1=O</smiles>

$2 \mathrm{R}=\mathrm{H}$

$3 \mathrm{R}=\mathrm{Me}$

$6 \mathrm{R}=\mathrm{AcNH}$ 

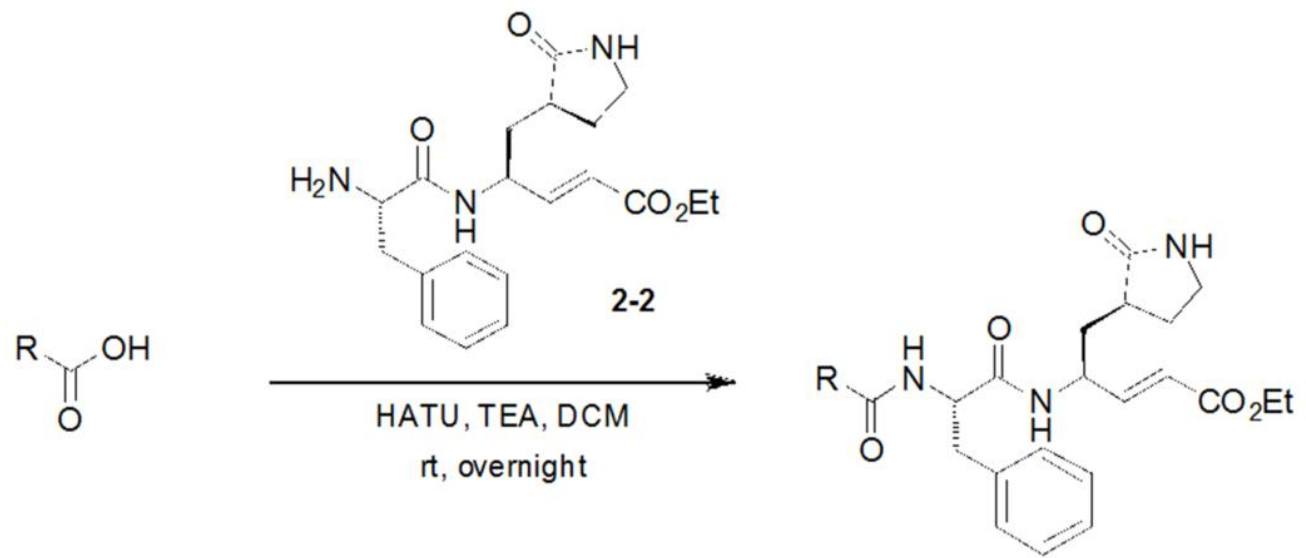

2-1a $\quad R=$ cyclopropylethyl

$7 \mathrm{R}=$ cyclopropylethyl

2-1b $\quad R=i-b u t y l$

$5 \quad \mathrm{R}=\mathrm{i}-$ butyl 


$$
\begin{aligned}
& \mathrm{R} \mathrm{NH}_{2} \longrightarrow \mathrm{a} \longrightarrow \mathrm{R} \underset{\mathrm{O}}{\mathrm{N}} \prod_{\mathrm{O}}^{\mathrm{O}} \longrightarrow \mathrm{b} \\
& \text { 3-1a } R=\text { cyclopropylmethyl 3-2a 3-3a } \\
& \text { 3-1b } R=\text { cyclobutyl }
\end{aligned}
$$<smiles>[R]CNC(=O)C(=O)N[C@@H](Cc1ccccc1)C(=O)N[C@H](/C=C/C[C@@H]1CCNC1=O)C[C@@H]1CCNC1=O</smiles>

$$
\begin{array}{ll}
8 & \mathrm{R}=\text { cyclopropylmethyl } \\
9 & \mathrm{R}=\text { cyclobuty }
\end{array}
$$

